\title{
Sociology and geography of growing seaweed in the Philippines
}

\author{
Edo Andriesse* \\ Seoul National University, Seoul, Republic of Korea
}

\begin{abstract}
The Philippines is a good example in the Asia and the Pacific of a country in which rural-urban migration has led to massive informal urban sectors and persistent urban poverty. Therefore, it also makes sense to continue exploring rural employment opportunities. This paper focuses on the impact of collective action dynamics on the livelihood resilience of Philippine's seaweed growing communities. Here we explain the successes and failures of collective action efforts among coastal communities in four Philippine provinces. The empirical insights are based on 41 semi-structured interviews (conducted in the Provinces of Guimaras, Palawan, Sorsogon, and Iloilo between 2016 and 2018) and 48 surveys in Iloilo (24 in 2015 and the same 24 seaweed farmers in December 2018). This contribution reveals the complexities of utilizing community support structures as a means of compensating for market and government failures. A gap continues to exist between collective action initiatives and household level capabilities.
\end{abstract}

Keywords: Seaweeds, Philippine, Farmers

\section{INTRODUCTION}

Coastal rural communities in Southeast Asia continue to be confronted with a wide range of vulnerabilities. Residents typically live near - and often on - the high tide line, making them more vulnerable to climate change, typhoons, the El Niño phenomenon, soil subsidence and increasing soil salinity. Many are farmers and fishers who find it difficult to sustain consistent levels of production from seafood (both capture and aquaculture) and agricultural crops (e.g. rice, vegetables). In addition, their livelihoods are profoundly influenced by resource management issues (overfishing, weak institutional arrangements) and market instability (price volatility, unscrupulous intermediaries, evolving product standards). As a result, millions of coastal households face persistent challenges in their attempts to escape poverty and achieve stable living standards with minimal risks of falling back (Ferrol-Schulte et al. 2013).

This article focuses on the impact of collective action dynamics on the livelihood resilience of Philippine's seaweed growing communities. Government agencies and civil society organizations generally have encouraged collective action. Yet, the strategies have not been able to facilitate the translation of economic growth into rural poverty reduction. The Philippine rural poverty incidence is still at $30 \%$, with coconut farmers and fishers the worst off. This contribution explains the successes and failures of collective action efforts among fishers in four Philippine provinces where cultivating carrageenan seaweeds is one of the primary income generators, or used to be one. The following questions are addressed:

1. Under what circumstances do seaweed associations and cooperatives thrive?

2. Has collective action resulted in more resilient livelihoods and a more inclusive seaweed value chain?

3. What are the implications for local governance and rural employment?

${ }^{*}$ Corresponding author: edoandriesse@snu.ac.kr 


\section{TRADITIONAL PERFORMING ARTS AND THE HISTORY OF LUDRUK RUKUN FAMILI IN SUMENEP}

The analysis of rural livelihoods has evolved from obtaining static livelihood snapshots towards adaptive livelihood strategies (de Haan \& Zoomers 2005). It recognizes how rural communities continuously weigh their options, capabilities and vulnerabilities. Alternative rural employment initiatives are fostered through various support mechanisms which depend on the national institutional frameworks, the effectiveness of decentralization schemes, the quality of disaster risk reduction programs, the presence of vertical chain coordination and the trust farmers and fishers have in market participation and government and NGO intervention. There is no single blueprint for improving smallholders' insertion in global agribusiness value chains.

In his book, Unplanned Development, Rigg (2012) demonstrates that development in Southeast Asia has been a complex mosaic of (unexpected) international, regional (sub-national), and household events rather than the outcome of structured national planning. Non-forecasted events seem to have had a deeper and longer lasting impact on households' livelihood trajectories and national pathways of development compared to the detailed stipulations formulated in five-year national development plans, including capitalist systems in the region. The International Fund for Agricultural Development (2016) identified five potential benefits of collective action in rural areas: expanding access to markets and finance, enhancing natural resource access and management, improving access to infrastructure, widening access to information and knowledge and strengthening voice and power in policy processes.

In coastal areas as well as large lake environments, successful grassroots associations and cooperatives are able to tackle one or more issues such as facilitating access to micro-finance, mitigating overfishing, co-managing mangrove forests, promoting coastal eco-tourism, improving preparedness for typhoons and floods and selling agricultural and aqua-cultural products collectively (Stobutzki et al. 2006; Lashley \& Warner 2015). However, the literature also identified complex dilemmas. The first dilemma is stakeholder competition (Ferrol-Schulte et al. 2013). Small-scale fishers, owners of large-scale fishing vessels, farmers who do not live near the shoreline and actors wishing to promote tourism have different interests with respect to coastal management and livelihood improvement efforts. A second dilemma is the intervening factor of local tensions. With respect to Vietnam, Van Hue and Scott (2008) argue that "coastal zones are areas of complexity, opportunity and conflict. They are naturally rich in resources but also fragile ecologies; they are narrow transition zones between land and ocean, and fresh and salt water, and are home to over half of Vietnam's people." Third is the possibility of collective action failure itself. The most disadvantaged groups are often "discouraged from participating in decision making" (Sick et al. 2014).

\section{METHODS}

Data for this study are primarily derived from 41 semi-structured surveys and 48 surveys in Iloilo with key informants and seaweed farmers/fishers in 10 municipalities across the provinces of Guimaras, Palawan, Sorsogon, and Iloilo. These provinces were chosen for their accessibility, variation in seaweed growing environments, promotion of seaweed by the Bureau of Fisheries and Natural Resources (BFAR) (2016) and diversity in developmental geographical settings. The insights obtained cover from 23 Barangays (lowest administrative level in the Philippines). Mindanao provinces are some of the top seaweed producers in the country, with the region comprising $62 \%$ of the national production. Palawan is the top producing province in the country. Its long and slender island geography has also made growing conditions more variable, depending on the Barangays' locations. Guimaras and Sorsogon are in the middle of national seaweed production rankings, with 2016 outputs of around 686MT and 374MT respectively (CountrySTAT Philippines 2017). They are increasingly struck by typhoons such as Typhoon Haiyan in 2013 and Typhoon Hagupit in 2014, making seaweed growing rather risky. Yet they receive extensive support in 
expanding seaweed production from multiple levels of government and international organizations because of the emphasis on livelihood diversification. Respondents were primarily composed of leaders from the fishing community, seaweed growers' associations and 24 seaweed growers whom we surveyed in both 2015 and 2018. The results from Iloilo provide a longitudinal dimension to this paper.

\section{GENERAL INSTRUCTIONS}

\subsection{Sorsogon}

In general, collective action efforts in all three provinces have indicated generally positive results. All four visited municipalities in Sorsogon have seaweed growers' associations; only in the Municipality of Pilar have associations ceased their activities. Interviews revealed that fraudulent market practices were widespread among growers and consolidators from 2000-2004, when seaweed prices were at their peak. Seaweeds naturally produce salt crystals during the drying process. When they have reached the required moisture content, they are packed in wicker-like baskets and sold in approximately $10 \mathrm{~kg}$ bundles. Growers at the same time knew that their local intermediaries or consolidators only performed visual and aesthetic checks on the products as quality control. Growers saw it as an opportunity to maximize their income by adding table salt to the bundles, thus also increasing its weight.

Sorsogon also hosts successful collective action efforts in the neighbouring Barangays of Bagaycay, Gubat and Carayat, in Prieto Diaz. Both have long-standing seaweed grower associations whose successes can be attributed to several factors. Seaweed growers in Barangay Bagacay are primarily members of the local Rural Improvement Club (RIC), composed of women whose ages range from 18 to 81 years old. They described themselves as a "self-help association," which started in 1981 with swine growing to enhance the livelihoods of women in the Barangay. Eventually, the group diversified their income sources with vegetables and rice farming. They built their own store to sell the produce to other residents. Seaweed growing only started in 2012, two years after BFAR introduced the idea. As the farms grew, other members became interested.

When asked about their group's success, the interviewees cited several factors. First is their strict implementation and adherence to RIC bylaws. They do not collect monthly dues, but members in good standing can have access to group's capital to start their own livelihoods. Members who do not attend the regular meetings or do not pay back their loans are expelled. Second is that they have numerous fundraising initiatives. Members are asked to contribute PhP 10 (US\$0.2) to the group fund per pig sold, while loans need to be repaid with interest. Third is recognizing group bonding and helping each other wherever necessary as key to member solidarity. Members are obligated to lend to those in need, attend meetings, or contribute $\mathrm{PhP} 1,000$ (US\$20.8) if a family member dies to cover funeral expenses. Similar factors are also present in the success of the seaweed growers' association in Barangay Carayat, Prieto Diaz. They have been growing seaweeds since 1995. Their farms, however, collapsed in 2002 after experiencing washouts from strong storms. Environmental conditions also deteriorated due to run-off from the mining operations on nearby Rapu-Rapu Island.

\subsection{Palawan}

Similar to Sorsogon, Palawan also experienced complete dissolution of collective action efforts in two Barangays. Seaweed growers' associations in Barangays Calawag and Bantulan in the municipality of Taytay have been completely disbanded. In both Barangays, these were the result of compounding environmental factors. Typhoon Queenie in 2014 had the largest impact, resulting in the complete washout of their farms. Recovery efforts were insufficient, with growers torn between immediate personal relief and farm recovery. The local government provided growers with seedlings and farm materials such as ropes, floaters, and plastic ties to help restart their farms. The number of seedlings, however, were insufficient for growers to earn a profit by the next harvest cycle. 
They would have to start as a nursery where the seaweeds are grown and cut only to expand their available stocks. During this stage, they could only dry small quantities of seaweed for sale. Out of nine investigated associations, seven can be described as successes in the sense that they continued to be active for several years post-inception, with others even counting decades of operations. Four out of nine associations said that they are considering becoming a cooperative. It is a move that greatly expands their collective action efforts, where the association itself acts as a profit-making entity using the paid-up capital collected from members for other growth opportunities.

There is, however, some hesitation in following through with these plans. Association leaders find the process too cumbersome to comply with. Two interviewees said that the required documents could only be acquired and submitted in the Palawan capital of Puerto Princesa. For many coastal Barangays, this is a difficult and expensive journey to undertake. Many areas are underserved by or do not have regular public transportation available due to their geographic isolation and unpaved roads. Further, those with access to vehicles would have to cover the petrol costs for a return trip over considerable distances. Interviewees also complained about the difficulty meeting the capital requirements to establish a cooperative. The Cooperative Development Authority, the Philippine agency regulating cooperatives, requires at least PhP 15,000 (US\$ 300) of paid-up capital for single-purpose cooperatives or those established to address one goal. What growers' associations have in mind, however, are multi-purpose cooperatives, entities that will fulfill various objectives. The required paid-up capital for multi-purpose cooperatives rises to at least PhP 100,000 (US\$ 2000)(Cooperative Development Authority 2015), a huge sum that associations find impossible to meet. Two interviewees also mentioned the presence of the Northern Palawan Fisher Folks Cooperative (NPFC), a recently formed cooperative in the province. NPFC's area of operation covers the municipalities of Roxas, Taytay and El Nido. An interviewee on Green Island, Roxas, mentioned it is one of their active buyers.

\subsection{Guimaras}

Compared to Sorsogon and Palawan, seaweeds cultivation has not fared well on Guimaras after 2010. Between 2000 and 2010 many coastal communities diversified into seaweeds, but a range of natural and human-made factors led to a gradual decline after 2010. According to several key informants, there were more than 700 seaweeds growers on Guimaras in 2010; only between 200 and 250 remained at the time of the fieldwork in 2016. The following factors contributed to the decline: the 2009-2010 El Niño, declining profit margins as a result of a higher price for seaweed seedlings and a lower seaweed farm gate price, a failing collective action effort between 2010 and 2012, the 2013 super Typhoon that washed out many seaweeds, the collapse of a seaweed buying firm in 2014 and the 2015-2016 El Niño.

According to the Province of Guimaras (2015), seaweed farmers on Guimaras utilising a marine area of 1,000 sq. meters can generate an "additional net income of PhP7,470 (US\$ 158) per cycle and they can do a maximum of five cycles in a year which means as much as PhP37,350 (US\$ 795) annual supplemental money for the family". And based on a study for the Island Barangay Panobolon (part of Nueva Valencia Municipality), the Panobolon United Fisher Folks Association (PUFA) could successfully implement a new project as part of the World Bank funded 2014-2021 Philippine Rural Development Programme (PRDP) and generate an additional income of PhP 26987 (US\$ 574) for participating households (Sea Knowledge Bank 2016). Nevertheless, these studies employ unrealistic assumptions. The calculations are based on five harvests per year yet, due to the factors described above, three harvests are more realistic and in line with the responses we obtained during the fieldwork. The fieldwork on Guimaras involved six Barangays: five in Sibunag Municipality and one in Nueva Valencia. In each of the four seaweed growing Barangays, there are active fishers and/or seaweed associations, but since many seaweed growers have stopped growing, they are less active than a few years ago. The most successful is Sabang Seaweed Growers Association with 300 members. During the fieldwork, around 100 members were actively engaged in seaweeds. In the future, this association hopes to diversify into seaweed chips, crackers, soap and potentially other products that can be manufactured in situ from seaweeds. In 2016, it was 
still waiting for PRDP funding. Seaweed successes before 2010 even led to the establishment of a cooperative in Sibunag Municipality in 2010. While it is too early to draw conclusions the first PRDP, implementation efforts in Guimaras Island paint a rather bleak picture.

\subsection{The difficulty to bring about alternative rural employment in Iloilo}

Iloilo Province is from a national perspective not a major seaweed producing region, yet BFAR has rolled out various programs in recent years to convince fisher folk to fish less and expand their livelihood sources. In Estancia and adjacent municipalities, typhoon Yolanda destroyed many fishing boats and washed away virtually all seaweeds in 2013. A first round of fieldwork early 2015 revealed how and to what extent environmental pressures were a cause of value chain vulnerabilities and disruptions. Not only do seaweed growers need to be constantly aware of the recurring typhoon threat and other environmental pressures, but they also occupy a marginal position within the value chain and do not have a stable income from selling dried seaweed. A second round of fieldwork late 2018 aimed at finding how the two local seaweed growing associations have evolved in recent years and how the seaweed growers have fared. This start of a longitudinal perspective has generated the following four observations:

- Out of 24 seaweed growers in 2015, only one is still engaged in seaweeds. The others have decided it was not possible to grow seaweeds anymore. Other typhoons such as Marce in 2016 and Ompong in 2018 washed away their seaweeds, and some had to stop growing because of a lack of capital to buy new seaweed seedlings or because they found the ocean water to be not clean enough. Some complained about chemical run-off from corn fields

- Associations have evolved. Compared to 2015 there is a new leadership, new members, and interestingly also some new beneficiaries of seaweed growing projects. The seaweeds growers of 2018 are not the same as the 2015. Those who stopped have stepped up fishing again. This result is quite problematic with respect to the perspectives of fostering inclusive value chains, reducing poverty and overfishing.

- Despite the challenges described above BFAR still appears to consider Estancia as a suitable site for seaweed. On the one hand it is true that seaweed growing households have at times enjoyed higher incomes. On the other hand, the multiple challenges coupled with the short-term nature of financial gains also gives rise to the question whether seeking alternative non-marine based livelihood opportunities would be more effective.

- As expected and as happened in other municipalities affected by Yolanda, there has been a large build-up of National Housing Authority housing communities who live within 40 meter of the shoreline, but many people prefer to stay near the beach and do not move to the new townhouses.

\section{TOWARDS A TRIUMVIRATE OF CIVIL SOCIETY, STATE AND MARKET?}

This article investigated to what extent community support structures and collective action, in particular associations and cooperatives, enabled seaweed growing communities in the Philippines to cope with environmental pressures, better navigate value chains and utilize value chain opportunities, and ultimately increase living standards. Our comparative analysis demonstrates that setting up associations and cooperatives does not guarantee success. There are mixed results. While a number of associations thrive in Sorsogon and Palawan, the situation in Guimaras and Iloilo has been more problematic, but also in the former two provinces there are cases of failure. The most successful association can be found in Barangay Bagacay in Gubat, Sorsogon. Strong community support and a diversified income structure has ensured longevity and effectiveness. On the other hand, there also have been cases where associations were dissolved either due to climate-related events, market failures or fraudulent practices.

Six factors appear to be important for thriving local collective action: (1) a substantial degree of financial literacy and planning capacities among the association leadership, (2) the absence 
of local tensions, (3) the presence of local social capital within the village, (4) the presence of non-marine livelihood options, (5) the inclusion of environmental threats in seaweed projects, and (6) opportunities to circumvent seaweed intermediaries and traders in order to gain higher prices.

Collective action can bring about more resilient livelihoods and a more inclusive seaweed value chains, but success is by no means guaranteed. In conclusion, this article reveals the complexities of utilizing community support structures as a means of compensating for market failures and government failures. A gap continues to exist between collective action initiatives and household level capabilities. Our empirical study offers two implications for state-civil society relations and processes of rural employment. First, initiating new livelihood projects through collective action, there is a need to focus more on path dependency and differentiated developmental-geographical settings. Still, admittedly, in situations in which local tensions continue to be disabling, it continues to be highly challenging to benefit from windows of opportunity to break out from locked-in vicious cycles and strengthen voices and power in policy processes. Second, large nationwide development interventions such as the World Bank-funded PRDP are only effective if the possibility of local failure is acknowledged. Seaweeds only thrive in clean ocean waters. It is increasingly recognized that markets, governments, and civil society can fail, but most development interventions do not build in the possibility of failure. Comprehensive investments need to be made for organizational development and capacity strengthening of seaweed growers associations. Only then can there be a triumvirate of civil society, state and market. Without strengthening associations, collective action efforts will continue to be in stasis, unable to successfully evolve towards higher forms of organizing, represent a larger constituency or influence the policy-making process. The challenge is thus to translate exogenous support mechanisms into endogenous processes of social capital formation.

\section{REFERENCES}

Bureau of Fisheries and Natural Resources (2016) Comprehensive National Fisheries Industry Development Plan. Quezon City: BFAR.

Cooperative Development Authority (2015) Revised guidelines governing the registration of cooperatives. Available at: http://cda.gov.ph/index.php/78-resources/issuances/memorandum-circulars-mcs/551mc-2015-01-revised-guidelines-governing-the-registration-of- cooperatives.

CountrySTAT Philippines (2017) CountrySTAT Philippines. Available at: http://countrystat.psa.gov.ph.

Ferrol-Schulte, D. et al. (2013) 'Sustainable Livelihoods Approach in tropical coastal and marine socialecological systems: A review', Marine Policy. doi: 10.1016/j.marpol.2013.03.007.

de Haan, L. and Zoomers, A. (2005) 'Exploring the frontier of livelihoods research', Development and Change. doi: 10.1111/j.0012-155X.2005.00401.x.

International Fund for Agricultural Development (2016) Rural Development Report 2016. Fostering inclusive rural transformation. Rome: International Fund for Agricultural Development.

Lashley, J. G. and Warner, K. (2015) 'Evidence of demand for microinsurance for coping and adaptation to weather extremes in the Caribbean', Climatic Change. doi: 10.1007/s10584-013-0922-1.

Province of Guimaras (2015) Provincial commodity investment plan.

Rigg, J. (2012) Unplanned Development. Tracking Change in South-East Asia. London and New York: Zed Books.

Sea Knowledge Bank (2016) Panobolon Unified Fisher Folks Association's (PUFA) Seaweed Production and Marketing Enterprise. Available at: http://seaknowledgebank.net/sites/default/files/icm_files/Panobolon Unified Fisherfolks Association's Seaweed Production and Marketing Enterprise_0.pdf.

Sick, D., Baviskar, B. and Attwood, D. (2014) Rural cooperatives: A new millennium? In V. Desai \& R. Potter. 3rd edn. Abingdon: Routledge.

Stobutzki, I. C., Silvestre, G. T. and Garces, L. R. (2006) 'Key issues in coastal fisheries in South and Southeast Asia, outcomes of a regional initiative', Fisheries Research. doi: 10.1016/j.fishres.2006.02.002.

Van Hue, L. T. and Scott, S. (2008) 'Coastal livelihood transitions: Socio-Economic consequences of changing mangrove forest management and land allocation in a commune of Central Vietnam', in Geographical Research. doi: 10.1111/j.1745-5871.2007.00492.x. 